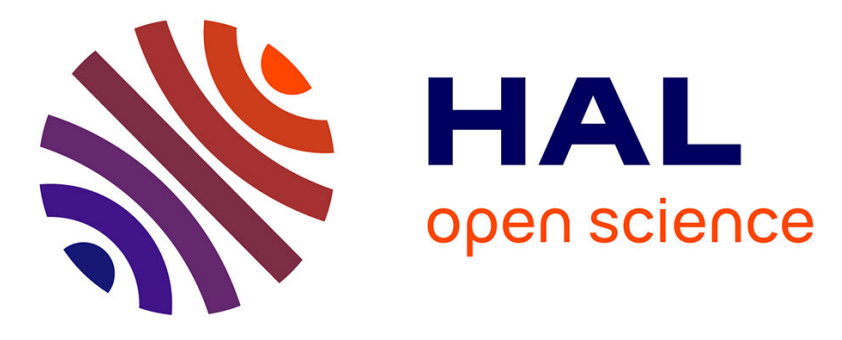

\title{
Impurity diffusion of cerium and gadolinium in single- and polycrystalline yttria-stabilized zirconia
}

Vincent Menvie Bekale, Anne-Marie Huntz, Corinne Legros, Gaël Sattonnay, François Jomard

\section{- To cite this version:}

Vincent Menvie Bekale, Anne-Marie Huntz, Corinne Legros, Gaël Sattonnay, François Jomard. Impurity diffusion of cerium and gadolinium in single- and polycrystalline yttria-stabilized zirconia. Philosophical Magazine, 2007, 88 (01), pp.1-19. 10.1080/14786430701708331 • hal-00513841

\section{HAL Id: hal-00513841 \\ https://hal.science/hal-00513841}

Submitted on 1 Sep 2010

HAL is a multi-disciplinary open access archive for the deposit and dissemination of scientific research documents, whether they are published or not. The documents may come from teaching and research institutions in France or abroad, or from public or private research centers.
L'archive ouverte pluridisciplinaire HAL, est destinée au dépôt et à la diffusion de documents scientifiques de niveau recherche, publiés ou non, émanant des établissements d'enseignement et de recherche français ou étrangers, des laboratoires publics ou privés. 


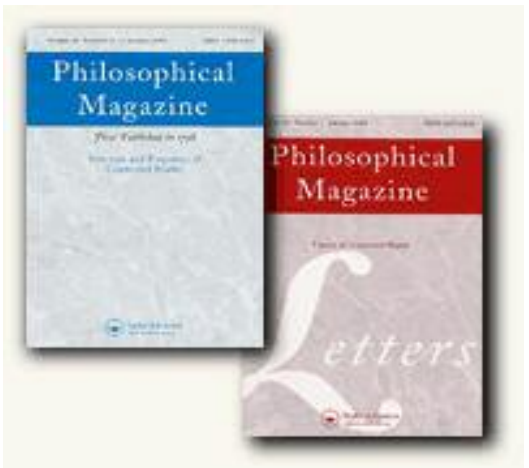

Impurity diffusion of cerium and gadolinium in single- and polycrystalline yttria-stabilized zirconia

\begin{tabular}{|c|c|}
\hline Journal: & Philosophical Magazine \& Philosophical Magazine Letters \\
\hline Manuscript ID: & TPHM-07-Apr-0108.R2 \\
\hline Journal Selection: & Philosophical Magazine \\
\hline $\begin{array}{r}\text { Date Submitted by the } \\
\text { Author: }\end{array}$ & 21-Sep-2007 \\
\hline Complete List of Authors: & $\begin{array}{l}\text { MENVIE BEKALE, Vincent; Univ. Paris Sud 11, ICMMO/LEMHE } \\
\text { Huntz, Anne-Marie; University Paris Sud, Essonne } 91 \\
\text { LEGROS, Corinne; Univ. Paris Sud 11, ICMMO/LEMHE } \\
\text { SATTONNAY, Gaël; Univ. Paris Sud 11, ICMMO/LEMHE } \\
\text { Jomard, François; CNRS, Groupe d Etude de la Matière condensée } \\
\text { (GEMaC) }\end{array}$ \\
\hline Keywords: & diffusion, SIMS \\
\hline Keywords (user supplied): & yttria stabilized zirconia, cerium, gadolinium \\
\hline
\end{tabular}

\section{(5) ScholaroNE \\ Manuscript Central}




\title{
Impurity diffusion of cerium and gadolinium in single- and polycrystalline yttria-
} stabilized zirconia V. Menvie Bekale ${ }^{1 *}$, A.M. Huntz ${ }^{1}$, C. Legros ${ }^{1}$, G. Sattonnay ${ }^{1}$, F. Jomard ${ }^{2}$

${ }^{1}$ Univ. Paris Sud 11, Laboratoire d'Etude des Matériaux Hors Equilibre, LEMHE-ICMMO, CNRS UMR 8182, Bât. 410, 91405 Orsay Cedex, France.

${ }^{2}$ Groupe d'Etude de la Matière Condensée (GEMaC), CNRS UMR 8635, 92195 Meudon, France.

Keywords: Diffusion, yttria-stabilized zirconia, cerium, gadolinium, SIMS

\begin{abstract}
Yttria-stabilized zirconia (YSZ) ceramic is considered as an attractive material for solid oxide fuel cells or for nuclear applications such as inert matrix for the destruction of excess plutonium and host material for nuclear waste storage. Long term properties as phase stability depend on cation diffusion. Therefore, the present work is focused on the diffusion study of Ce and Gd in YSZ single crystals and high density polycrystals. A thin film of Ce or Gd was deposited either by spin-coating method or by physical vapour deposition on the surface of polished samples. The diffusion experiments were performed from 1173 to $1673 \mathrm{~K}$ under air. The $\mathrm{Ce}$ or Gd diffusion profiles were determined by secondary ion mass spectrometry. The analysis of the penetration profiles led to the determination of bulk diffusion $\left(D_{b}\right)$ in single crystals and effective $\left(D_{\text {eff }}\right)$, bulk and grain boundary diffusion coefficients $\left(D_{\text {gb }}\right)$ were determined in polycrystals. The dependence of diffusion coefficients on temperature is described by means of Arrhenius equations and the diffusivity is compared with literature.
\end{abstract}

*Corresponding Author. Tel : 331691548 13, fax : 33169154819

E-mail address : vincent.menvie@lemhe.u-psud.fr

\section{Introduction}

Yttria-stabilized zirconia (YSZ) is one of the most technologically important ceramic materials. It is widely used as electrolyte material in solid oxide fuel cells, oxygen sensors, oxygen separation membranes and thermal coating barriers. It is also considered as one of the most promising materials for use as inert matrix for the destruction of excess plutonium or good host material for nuclear waste storage [1]. These applications are based on refractory properties, high chemical durability, excellent radiation stability and the ability to form solid solutions in a wide range of solubilities with some actinide elements ( $\mathrm{Pu}, \mathrm{U}, \mathrm{Th})$ [2-4]. Furthermore, its 
stability in operating conditions mainly depends on the slow cation transport, which controls processes such as creep, migration of dopants and impurities. Generally, some actinide elements contained in high-level radioactive wastes can be simulated by rare earths : cerium as tetravalent actinide and gadolinium as trivalent actinide. Up to now, some studies have been performed to determine cation bulk diffusivities in cubic stabilized zirconia [5-10], and to a much lesser extent to determine cation grain boundary diffusion coefficients [5-8]. The present work is focused on a comparative study of both Ce and Gd diffusion in single crystalline YSZ (9.5 mol\% of yttria) and high density polycrystalline YSZ (8 and $10 \mathrm{~mol} \%$ of yttria).

\section{Experimental}

\subsection{Material}

The YSZ polycrystals were prepared from high-purity powder $8 \mathrm{~mol} \%$ (8YSZ) and $10 \mathrm{~mol} \%$ (10YSZ) yttria stabilized zirconia supplied by Tosoh Co. Ltd., Tokyo, Japan. These powders were cold isostatically pressed at $250 \mathrm{MPa}$ and sintered in air at $1723 \mathrm{~K}$ for $168 \mathrm{~h}$ with heating and cooling rate of $5 \mathrm{~K} / \mathrm{min}$ [11]. From the sintered rods, round pellets were cut with nominal dimensions of $10 \mathrm{~mm}$ diameter and $2 \mathrm{~mm}$ thickness. Pellets were then polished using diamond pastes down to $1 / 4 \mu \mathrm{m}$ and further annealed in air for $10 \mathrm{~h}$ at $1673 \mathrm{~K}$ in order to eliminate polishing stresses. The micrograph of a thermal-etched 8YSZ sample obtained by scanning electron microscopy (SEM, figure 1) shows grains with an average diameter of $5 \mu \mathrm{m}(2-10$ $\mu \mathrm{m})$. The density of the samples was measured by Archimedes method and full dense samples with relative density of $99.5 \%$ of the theoretical one were obtained. Moreover, the homogeneity and composition were checked by X-ray diffraction (XRD), Rutherford backscattering (RBS) and electron microprobe. XRD patterns indicate that samples only exhibit the lines of the cubic fluorite-type structure.

Furthermore, $9.5 \mathrm{~mol} \%$ yttria stabilized zirconia (9.5YSZ) pure single crystals $<100>$-oriented supplied by Crystal GmbH, Berlin, Germany, were also investigated. Specimens with dimensions of $5 \mathrm{~mm} \times 5 \mathrm{~mm} \times 1 \mathrm{~mm}$ were cut and used as-received.

\subsection{Diffusion experiments}

By the spin-coating method, a thin layer of $\mathrm{CeO}_{2}$ and $\mathrm{Gd}_{2} \mathrm{O}_{3}$ was deposited on the YSZ substrates. Ammonium cerium nitrate or gadolinium nitrate were used as starting materials. Each salt was dissolved in distilled water. Then, few drops of nitric acid as well as citric acid and ethylene glycol were added to the stirred clear solution. This mixture was heated using a hot-plate in a ventilated fume hood to decompose nitrates and to get a viscous solution. After cooling, the solution was dropped onto the polished surface of the YSZ samples. After drying, a 
thermal annealing at $573 \mathrm{~K}$ for $30 \mathrm{~min}$ followed by $10 \mathrm{~min}$ at $973 \mathrm{~K}$ was applied in order to obtain an adherent coating. The thickness of the ceria or gadolinia film was estimated on a asdeposited sample via a SIMS (secondary ion mass spectrometry) profile and a measurement of the crater depth with a profilometer. The thickness is about of $70 \mathrm{~nm}$, as shown in figure $2 \mathrm{a}$. Additionally, physical vapour deposition technique (PVD) performed by THEVA GmbH was used for producing $\mathrm{CeO}_{2}$ regular thin films from metal cerium targets at $953 \mathrm{~K}$. The thickness of the so-obtained ceria film was also estimated on as-deposited sample to be about $80 \mathrm{~nm}$, as shown in figure $2 \mathrm{~b}$. The main difference is that the film deposited by the spin coating method exhibits a somewhat irregular and a rough surface, which is not the case for the $\mathrm{CeO}_{2}$ film obtained by PVD. For the Ce profile obtained on as-deposited samples (Fig. 2a and b), a curve tail can be distinguished. In fact, the samples have been subjected to a thermal annealing after the deposition of Ce: at $973 \mathrm{~K}$ and at $953 \mathrm{~K}$ for a coating performed by spin coating or by PVD, respectively. This heating is responsible for the slight penetration of the tracer before the diffusion experiments.

The Ce and Gd diffusion experiments were performed in air from 1173 to $1673 \mathrm{~K}$. An attempt of cerium diffusion was made at $873 \mathrm{~K}$ with the hope to determine bulk diffusion coefficients at very low temperature (Fig.2c), but it was not satisfying and such temperature were discarded further on. At the end of the annealing, the sample was quenched by pulling it out from the furnace. The diffusion annealing time and temperature, reported in Table 1, were chosen so that most of the experiments correspond to a B-type diffusion regime [12], which means that both bulk and grain boundary diffusion coefficients can be determined. Nevertheless, some diffusion tests were performed in $\mathrm{C}$ regime which leads only to determine diffusion coefficients in the grain boundaries.

\subsection{Depth profiling by secondary ion mass spectrometry (SIMS)}

The cerium and gadolinium depth profiles were established by secondary ion mass spectrometry (Cameca IMS4F-CNRS/Meudon/France), using either $\mathrm{O}_{2}^{+}$or $\mathrm{Cs}^{+}$primary ion source with energy of $10 \mathrm{keV}$. For cerium and gadolinium analysis, the evolution of ${ }^{140} \mathrm{Ce}$ and ${ }^{142} \mathrm{Ce},{ }^{158} \mathrm{Gd}$ and ${ }^{160} \mathrm{Gd}$ signals were recorded and ${ }^{140} \mathrm{Ce}$ and ${ }^{158} \mathrm{Gd}$ were retained since each of them corresponds to the most intense isotope. They excluded also any possible interference, for instance between $\mathrm{Gd}$ and $\mathrm{Nd}$. For gadolinium, the $\mathrm{GdO}^{-}$ion was analysed. The scanned area was $150 \mu \mathrm{m} \times 150 \mu \mathrm{m}$ and the analyzed zone was limited by a diaphragm to $33 \mu \mathrm{m}$ diameter. Such a size of the analyzed area compared to the grain size of polycrystalline samples will lead to average diffusion coefficients, as it is usual when working on polycrystalline materials. The availability of the results was verified by performing several analyses on different areas of the 
same sample. To avoid sample charging effects on sputtering, a normal electron flood gun was used and a $30 \mathrm{~nm}$ thick gold layer was deposited on the samples. The limit of detection of the apparatus is given as 1 count per second. After establishing the penetration profile, $I=f(t)$ by SIMS analysis (Fig.3a), the crater depth was measured using a profilometer (KLA Tencor P1). A typical crater profile is given in figure $3 \mathrm{~b}$. This measurement allowed to convert the sputtering time into eroded depth, as shown in figure $3 \mathrm{c}$.

\subsection{Determination of bulk and grain boundary diffusion coefficients}

In a first step, the cation ( $\mathrm{Ce}$ or $\mathrm{GdO}$ ) signals were normalised by zirconium signal which can be considered as constant in the material (see Fig.2c), thus leading to the diffusing element concentration. It appeared that there was no difference in the diffusion coefficients between the analysis of the concentration and the direct analysis of the Ce or Gd intensity. As an example, results obtained for the experiment made on $8 \mathrm{YSZ}$ at $1373 \mathrm{~K}$ were analysed with either the concentration profile $\mathrm{I}_{\mathrm{Ce}} / \mathrm{I}_{\mathrm{Zr}}$ or the cerium intensity $\mathrm{I}_{\mathrm{Ce}}$ profile, as a function of the depth, and will be compared with others in $\S 3$.

Thus, further on, $\mathrm{Ce}$ and Gd profiles were directly considered. In the same way, the similarity in the analysis of intensity or concentration for which the background has been subtracted indicates that it is not necessary to subtract it. Once again, for the experiment made on $8 \mathrm{YSZ}$ at 1373 K (Figs.3), diffusion coefficients were also calculated from the concentration profile after having subtracted the background, and they will be compared with other results, later on $(\S 3)$. Another mode to avoid problems due to the sputtering rate consists in verifying that the primary current is constant. It was done during the analyses and maximum variations of 5\% were observed. It means that the concentration variations are negligible in regard to the uncertainty of diffusion coefficients. Concerning the drift of the background (value of the signal given by an element when it is absent from the matrix), as there is no matrix signal drift, the background cannot present a drift and cannot be responsible for the appearance of a curve tail. According to our experiments, this background is often varying between 5 and 10 counts per second (see Figs.2c and 7a).

Another point which has to be discussed concerns the film roughness variations according to the deposition method. Indeed, the curve tails could be affected by the roughness. But, though the roughness of the films deposited by the spin coating method is higher than the roughness of films obtained by PVD, it was observed that the diffusion coefficients obtained from experiments with spin coating deposition are not different from those obtained from PVD. Thus, the influence of the roughness can be neglected. 
For polycrystals, two distinct regions can be determined on the $\mathrm{Ce}$ or $\mathrm{Gd}$ diffusion profiles (Figs.4 and 5) at temperatures higher than 1173K (diffusion in B regime) : (i) near the surface, a fast decrease of the concentration is observed (region 1) and (ii) far from the surface, the concentration slowly decreases (region 2). The concentration near the surface should correspond to the contribution of either bulk diffusion or effective diffusion, while the concentration far from the surface, i.e. the curve tail, should correspond to the grain boundary diffusion [13].

From region 1 (Figs.4b and $5 b$ ), an effective diffusion coefficient $D_{\text {eff }}$, i.e. bulk diffusion with contribution of grain boundary diffusion, was determined using a solution of the Fick's second law for diffusion from a thin layer of the deposited tracer [13]:

$$
\frac{C(x)}{C_{0}}=\exp \left(-\frac{x^{2}}{4 D_{\text {eff }} t}\right)
$$

The comparison of the bulk diffusion penetration and the deposited film thickness suggests that, in some cases, the thick film solution of Fick's equations should be used. It was done, for instance in the case of cerium diffusion in 10YSZ at $1473 \mathrm{~K}$. The analysis with the thick film solution led to the same diffusion coefficients, so that the thin film solution was used further on.

From the tail of the profile (region 2), the Whipple / Le Claire model [14] was used to determine the parameter $\delta \alpha \mathrm{D}_{\mathrm{gb}}$ using the following equation:

$$
\alpha \mathrm{D}_{\mathrm{gb}} \delta=0.661\left[-\frac{\partial(\ln \mathrm{C})}{\partial \mathrm{x}^{6 / 5}}\right]^{-5 / 3}\left(\frac{4 \mathrm{D}_{\mathrm{b}}}{\mathrm{t}}\right)^{1 / 2}
$$

where $D_{g b}$ is the grain boundary diffusion coefficient, $\delta$ is the grain boundary width and $\alpha$ is a dimensionless segregation factor [13]. According to this model, a plot of $\ln C$ versus $x^{6 / 5}$ should yield a straight line for the experimental points corresponding to region 2 and the slope of this straight line (Figs.4c and 5c) allows the determination of : $\left[-\frac{\partial(\ln C)}{\partial x^{6 / 5}}\right]^{-5 / 3}$.

Hart's equation [15] was then used to relate the effective diffusion coefficient with the bulk diffusion coefficient $\left(D_{b}\right)$ and with the grain boundary diffusion coefficient through the following relationship:

$$
D_{\text {eff }}=f \alpha D_{g b}+(1-f) D_{b}
$$

where $f$ is the fraction of atomic sites located on the grain-boundaries. $f$ may be calculated through the expression $\mathrm{f}=3 \delta / \phi[13]$ where $\phi$ is the grain size of polycrystal and $\delta$ the grain 
boundary width, conventionally taken as $1 \mathrm{~nm}$ [16]. In the present study, $\mathrm{f}$ is thus equal to $6 \times 10^{-4}$ for all polycrystalline samples.

It can be noted that such equations (1-3) can be used to analyze curve tails obtained in single crystals in which aligned dislocations, i.e. sub-boundaries, are present [13].

In the case of C-type regime experiments [12], which concerns experiments performed at $1173 \mathrm{~K}$, bulk diffusion is not detected, because of the small tracer penetration. Then the first region is associated to grain boundary diffusion, as shown in figure 6 . The parameter $\alpha D_{g b}$ is determined by the following equation:

$$
\frac{C(x)}{C_{S}}=\operatorname{erfc}\left(\frac{x}{2 \sqrt{\alpha D_{g b} t}}\right)
$$

where $\mathrm{C}_{\mathrm{S}}$ is the diffusing element concentration at the surface. A second region appears in the diffusion curves due to the transport of cerium or gadolinium in the residual porosities.

For single crystals, the diffusion profile should show only one region corresponding to a fast decrease of the intensity and related to the bulk diffusion. Thus, the bulk diffusivity can be obtained from eqn.1 (diffusion from thin layer) by replacing $D_{\text {eff }}$ by $D_{b}$ :

$$
\frac{C(x)}{C_{0}}=\exp \left(-\frac{x^{2}}{4 D_{b} t}\right)
$$

\section{Results}

Figures 3 to 8 show various penetration profiles and analyses of these profiles. At first, it was checked that both tracer deposition methods (PVD and spin coating) lead to similar results. Thus, diffusion experiments at $1673 \mathrm{~K}$ were performed for two days with a Ce film deposited either by the spin coating method or by PVD on the samples. The experimental values deduced from samples with PVD coating of ceria are also given in Table 1. No significant difference between the deposition methods is observed. Moreover, for the experiment performed on 8YSZ at $1373 \mathrm{~K}$, the results obtained when analysing the concentration profiles and when subtracting the background are given in italics in Table 1 with other results, relative to intensity profiles without subtracting the background. It can be seen that the differences with the diffusion coefficient values retained in this study are smaller than the uncertainty on diffusion coefficients.

As a general case, the penetration profiles in polycrystals show two regions corresponding to different diffusion mechanisms (Figs.3-6). According to a B regime (see Table 1), the first part 
of the profile corresponds to effective diffusion and the second part of the profile, i.e. the curve tail, is characteristic of the diffusion along grain boundaries. More precisely, the slope of the straight line $\ln I=f\left(x^{2}\right)$ in the first part (Figs. $4 b$ and $5 b$ ) corresponds to the theoretical diffusion profile given by eqn.1 for effective diffusion. In the second part (Figs.4c and 5c), the slope of the straight line $\ln I=f\left(x^{6 / 5}\right)$ corresponds to the gradient $-\partial \ln C / \partial x^{6 / 5}$ necessary to solve eqn. 2 . Similar profiles were obtained also for diffusion experiments established in C-type regime (see Table 1 and Figs.6a and 6c), though it was expected to obtain only one part in the diffusion profile. In this case, the first part of the profiles is related to grain boundary diffusion and the slope of the straight line obtained in figures $6 \mathrm{~b}$ and $6 \mathrm{~d}$ correspond to the theoretical diffusion profile given by eqn.4. The second part of these profiles is associated to the diffusion in the residual porosity in our sintered samples.

For single crystals, only one region associated to bulk diffusion was expected in the penetration profile. This was effectively obtained at high temperature $(1673 \mathrm{~K})$ as shown in figure $7 \mathrm{a}$. According to eqn.1, the slope of the plot $\ln I=f\left(x^{2}\right)$ (Fig.7b) leads to the value of the bulk diffusion coefficient. However, at smaller diffusion temperatures (1473 and $1373 \mathrm{~K}$ ), two regions are observed (Fig.8a). Plotting the logarithm of the intensity versus $x^{2}$ in the first part leads to a diffusion coefficient which should be reasonably associated to bulk diffusion. At both temperatures the second part of the profiles satisfies eqn.2 (Fig.8c). The mechanism which leads to this second part will be discussed further on.

From all these profiles, according to the procedure explained in $\$ 2.4$, bulk, effective and grain boundary diffusion coefficients $\left(\alpha \mathrm{D}_{\mathrm{gb}} \delta\right)$ were obtained. All the values are gathered in Table 1 . The diffusion coefficients obtained for polycrystals are plotted as a function of the inverse temperature in figures $9 \mathrm{a}$ and $9 \mathrm{~b}$, and activation energy values deduced from the Arrhenius lines are given in Table 2.

\section{Discussion}

From figure 9, some differences appear either in the diffusion coefficients or in the activation energies. These differences are discussed according to the possible influence of various parameters successively.

\subsection{Bulk diffusion and grain boundary diffusion in cubic stabilized zirconia}

As expected, the grain boundary diffusion is higher of about 5 orders of magnitude than the bulk diffusion as in literature, for instance results of Oishi et al. [5-7] and Kowalski et al. [8]. 
The activation energy of bulk diffusion is of the same order of magnitude than that suggested by Kilo et al. [9] for a diffusion process via cationic vacancies. In most cases of literature data, the activation energies for bulk diffusion are between $390 \mathrm{~kJ} / \mathrm{mol}$ and $540 \mathrm{~kJ} / \mathrm{mol}$, which is close to our values (Table 2). However, from figures 9-10 and Table 2, it appears that the activation energy of grain boundary diffusion is included between $500 \mathrm{~kJ} / \mathrm{mol}$ and $600 \mathrm{~kJ} / \mathrm{mol}$. These values are at least equal or even higher than the activation energies of bulk diffusion. According to Monty and Atkinson [17], the activation energy for grain boundary diffusion in oxides should be roughly $2 / 3$ of the activation energy of bulk diffusion. It is not the case for our results and that is one reason at least for expressing $\alpha D_{g b}$ rather than $D_{g b}$. The $\alpha$ factor is a way to express that the diffusing impurity concentration changes in the grain boundaries during the impurity diffusion and it depends on the interaction between the diffusing impurity and the grain boundaries, but also on other species segregating [18]. This affects the grain boundary diffusion profiles by changing their slopes and leads to apparent grain boundary diffusion coefficients. Thus, as suggested in other studies performed on oxides [19-20], the high activation energy obtained in this study could be related to segregation or precipitation phenomena along grain boundaries, but we do not have evidence of such a phenomenon.

\subsection{Effect of yttria content in cubic stabilized zirconia}

Figure 10 gathers all the results on 8 YSZ and on 10YSZ polycrystals. In the temperature range and the yttria amount studied here, the diffusion coefficients along grain boundaries do not seem to be dependent on the yttria content. Nevertheless, the Arrhenius lines associated to Ce or Gd diffusion in 10YSZ have a higher slope than the lines associated to diffusion in 8YSZ : activation energies of $506 \pm 12 \mathrm{~kJ} / \mathrm{mol}$ (Ce diffusion) and $507 \pm 8 \mathrm{~kJ} / \mathrm{mol}$ (Gd diffusion) in $8 Y S Z$ are obtained whereas values of $599 \pm 88 \mathrm{~kJ} / \mathrm{mol}$ (Ce diffusion) and $582 \pm 19 \mathrm{~kJ} / \mathrm{mol}$ (Gd diffusion) are determined in 10YSZ. Consequently, it can be expected that at lower temperatures the grain boundary diffusion would be slower in 10YSZ than in 8YSZ, possibly on account of yttria segregation along grain boundaries when its amount increases. The recent analysis of M. Kilo [21] does not exclude this possibility and, as suggested above, the high values of grain boundary diffusion activation energies could be justified by such a segregation phenomenon.

Concerning bulk diffusion, differences are slightly higher, but are not clearly related to the yttria content. Indeed, cerium diffusion is slightly higher in 10YSZ, while gadolinium diffusion is slightly higher in 8YSZ (Fig.10). In other words, bulk diffusivity in 8YSZ is enclosed by bulk diffusivity in 10YSZ. Kilo et al. [9], with an higher yttria content, observed a decrease of 
the cation self-diffusion, since cation diffusion probably occurs via the zirconium vacancy $\mathrm{V}_{\mathrm{Zr}}^{4^{\prime}}$. So, the cationic vacancy amount decreases when the yttria content increases, leading to a slowing of cation diffusivity which should be detected. It is not so clear in our study, perhaps due to the fact that the yttria content range is small.

Consequently, in the narrow yttria content range studied here, it can be considered that there is no significant effect of this content on the diffusivity.

\subsection{Comparison of cerium and gadolinium diffusivities}

The Ce bulk diffusivity (Fig.10) is slightly higher than that of Gd in both 8YSZ and 10YSZ. Considering the ionic radius of cerium $\left(\mathrm{Ce}^{4+}\right)$ and gadolinium $\left(\mathrm{Gd}^{3+}\right)$, respectively $0.097 \mathrm{~nm}$ and $0.1053 \mathrm{~nm}$ [22], it seems that the higher diffusion of cerium in 8YSZ and 10YSZ is associated to its smaller ionic radius. Note that the ionic radii are given with the assumption that these elements are eightfold-coordinated, as it can be expected from the fluorite cubic structure. So, it can be concluded as also remarked by Kilo [21] that the bulk diffusion decreases when the ionic radius increases.

No influence of the size effect is seen on the grain boundary diffusion. The cerium and gadolinium grain boundary diffusion coefficients are very close in polycrystals (Fig.10). Indeed, in the case of grain boundary diffusivity, the correlation between $\mathrm{D}_{\mathrm{gb}}$ and the ionic radius of the diffusing species is not obvious. For instance, although $\mathrm{Ca}^{2+}$ ionic radius is very high, it diffuses faster than other diffusing species with a smaller ionic radius [9, 21].

For an application as transmutation matrix of actinides, it is interesting to note that Ce diffusion or Gd diffusion is nearly as slow as the host cation self-diffusion $(\mathrm{Zr})$ in yttria-stabilized zirconia [9, 21]. In fact, cerium or gadolinium is used in the present work to simulate the actinides that will be incorporated in zirconia matrix and transmuted into nuclear reactor. So, it is preferable that these radioactive elements should diffuse slowly through the ceramic under the thermal neutron flux during irradiation experiments in which the temperature was calculated to be more than about $1773 \mathrm{~K}$ [23].

\subsection{Diffusion in single crystals}

Coming to results concerning the diffusion of cerium in single crystals, it can be observed on figure 11, (Table 1), that bulk diffusion, deduced from the first part of the experimental curves (if two parts in the curve), is higher than in polycrystals. It was verified that the single crystals were not heterogeneous, without porosity and without secondary phase, which could be at the origin of the diffusivity increase. 
In a first step, it was considered that two types of point defects could ensure the cation diffusion, as suggested by Solmon in her study on anionic self-diffusion in YSZ single crystals $[24,25]$. But, such a phenomenon, if it exists, should also act in polycrystalline materials, which is not the case, and, besides, it is unlikely that complex defects would lead to faster diffusion.

It can also be remarked that the bulk diffusivity determined in our study in 9.5 YSZ single crystal are similar to the bulk diffusion coefficients obtained by Taylor [10] on a 11.1YSZ single crystal (Fig.11) : the values of $D_{b}$ obtained in single crystals are always higher than the ones obtained in polycrystals. In the case of Taylor et al., it could be due to the difference in yttria content. However, a higher yttria amount should lead to a decrease of the bulk diffusion coefficients, as mentioned in $\S 4.2$. Thus, the difference in yttria content between our single and polycrystals cannot account for the difference in bulk diffusivity.

It should be considered that the evolution of the cationic dopant concentration could influence the bulk diffusion coefficient. Again, with such an assumption, the influence would also be detected in the case of diffusion in polycrystals. Moreover, according to the small concentration of cationic dopant, it can be considered that the dopant diffusing atoms (Ce or $\mathrm{Gd}$ ) are always surrounded by host atoms, which corresponds to the solution of Fick equations for thin films [13].

Another possibility is that the diffusion coefficient deduced from the first part of the profiles for single crystals should be disturbed by diffusion in short-circuits. In this case, the two parts of our curves, obtained only at the lowest temperatures (1373 and $1473 \mathrm{~K}$ ), would be associated to effective diffusion for the first part and diffusion in dislocations for the second part. If the dislocations are aligned in sub-boundaries, the profiles obtained at 1473 and $1373 \mathrm{~K}$ can be analysed as for the grain boundaries, using eqns. 1-3 (see $§ 2.4$ ) [13]. Then, analysis of the first part would lead to an effective diffusion coefficient, but, in order to solve equation 3 , a fraction of atoms diffusing along the sub-boundaries has to be chosen. Calculations performed to obtain bulk diffusion coefficients in single crystals similar to those concerning diffusion of cerium in $8 Y S Z$ and 10YSZ polycrystals lead to a f value of the same order of magnitude than the f value of polycrystals $\left(\sim 5 \times 10^{-4}\right)$. Taking into account the relatively small dislocation density in such materials, this fraction of diffusing atoms in sub-boundaries is too important, and the analysis was not pushed further on. Nevertheless, it is likely that, in single crystals, the first part of the penetration profiles does not correspond to bulk diffusion only but may be disturbed by dislocations and/or by sub-boundary diffusion. Our results suggest that results of Taylor [10] 
correspond also to overestimated bulk diffusion coefficients, diffusion being disturbed by subboundaries.

Finally, it is important to note that, according to a recent work on anisotropic dielectric properties in 8YSZ [26], it was found that oxygen ions easily diffuse along the $<100>$ direction. In oxides, anisotropy of cationic diffusion was already observed, for instance in $\mathrm{Cr}_{2} \mathrm{O}_{3}$ [27] and in $\mathrm{Fe}_{2} \mathrm{O}_{3}$ [28, 29 and see also 13]. It was also observed in native oxides such as $\mathrm{NiO}$ [30]. Even if our diffusion data could be partially increased by diffusion along sub-boundaries, a crystallographic orientation effect could also explain the higher values of the bulk diffusion coefficients, as the single crystals investigated in the present work and those used by Taylor et al. [10] are oriented along [100],

\subsection{Comparison with other literature data}

Comparison with literature data is made in figures 12 and 13. The activation energy of bulk diffusion of all results is of the same order of magnitude and close to the value expected for a diffusion process via cationic vacancies [9]. There is agreement with the effect of the ionic radius of the diffusing species: in Taylor study as in our study, cerium diffuses slightly faster than gadolinium, confirming that the size of the diffusing species plays a major role in the bulk cation diffusion mechanism.

In a recent analysis of results on tracer diffusion in YSZ [21], it is suggested that, while the cation bulk diffusion should be mainly ruled by ionic size effects, cation grain boundary diffusion might be dominated by charge effects. This classification does not seem so clear from figure 13 where grain boundary diffusion data are gathered. Indeed, the charge of $\mathrm{Gd}^{3+}$ ions and of $\mathrm{Ce}^{4+}$ ions is different but their grain boundary diffusivity is very close. $\mathrm{Ti}^{4+}$ which has the same charge than $\mathrm{Zr}^{4+}$ ion diffuses very fastly. The diffusivity of $\mathrm{Ca}^{2+}$ is still faster than the diffusivity of other cations, although the ionic radius of $\mathrm{Ca}^{2+}$ is higher $(0.112 \mathrm{~nm})$ than those of $\mathrm{Gd}^{3+}(0.1053 \mathrm{~nm})$ and of $\mathrm{Ce}^{4+}(0.097 \mathrm{~nm})$.

\section{Conclusion}

The diffusion study of $\mathrm{Ce}$ and Gd in 9.5YSZ single crystals and in 8YSZ and 10YSZ high density polycrystals from 1173 to $1673 \mathrm{~K}$ in air, led to the following results:

1. The grain boundary diffusion $\mathrm{D}_{\mathrm{gb}}$ is higher (about 5 orders of magnitude) than the bulk diffusion $D_{b}$.

2. For the narrow yttria content range used in this study, there is no significant effect of the composition on the diffusivities in polycrystals. The cation bulk diffusivity in YSZ 
seems to be correlated to the ionic radius of the diffusing species: the higher the ionic radius, the slower the bulk diffusion.

3. In YSZ single crystal, it is suggested that the penetration profile corresponds to an effective diffusion coefficient $\mathrm{D}_{\text {eff }}$, and not to a bulk one $\mathrm{D}_{\mathrm{b}}$, due to the presence of subboundaries. Moreover, the higher bulk diffusion coefficient in single crystals (when compared to polycrystals) can be related to anisotropy effects: it is possible that easy diffusion occurs along [100] direction.

4. The activation energies for bulk diffusion are similar in both single crystals and polycrystals. The comparison of the bulk diffusion activation energy with the literature suggests that cation diffusion occurs via cation vacancy $\mathrm{V}_{\mathrm{Zr}}^{4^{\prime}}$. The Ce or Gd diffusion is as slow as the host cation self-diffusion $(\mathrm{Zr})$ in yttria-stabilized zirconia.

5. The activation energies have the same order of magnitude for both bulk diffusion and grain boundary diffusion, even higher for grain boundary diffusion in some cases. This result could be related to segregation phenomena along grain boundaries. 


\section{References}

1. W.L. Gong, W. Lutze, R.C. Ewing, J. Nucl.Mater. 277, 2000, 239.

2. D.F. Carroll, J. Am. Ceram. Soc., 46, 1963, 195.

3. I. Cohen, B.E. Schaner, J. Nucl. Mater., 9, 1963, 18.

4. F.A. Mumpton, R. Rustum, J. Am. Ceram. Soc., 43, 1960, 237.

5. Y. Oishi, H. Ichimura, J. Chem. Phys., 71, 1979, 5134.

6. Y. Oishi, Y. Sakka, K. Ando, J. Nucl. Mater., 96, 1981, 23.

7. Y. Sakka, Y. Oishi, K. Ando, J. Mater. Sci., 17, 1982, 3101.

8. K. Kowalski, A. Bernasik, A. Sadowski, J. Eur. Ceram. Soc., 20, 2000, 2095; ibid 951.

9. M. Kilo, G. Borchardt, B. Lesage, O. Kaïtasov, S. Weber, S. Scherrer, J. Eur. Ceram. Soc., 20, 2000, 2069.

10. M.A. Taylor, C. Argirusis, M. Kilo, G. Borchardt, K.D. Luther, W. Assmus, Solid State Ionics, 173, 2004, 51.

11. V. Menvie Bekale, C. Legros, C. Haut, G. Sattonnay, A.M. Huntz, Solid State Ionics, 177, 2006, 3339-3347.

12. L.G. Harrison, Trans. Faraday Soc., 57, 1961, 1191.

13. J. Philibert, "Atom Movements, Diffusion, and Mass Transport in Solids". Les Editions de Physique, Les Ulis, France, 1991.

14. A.D. Le Claire, Brit. J. Appl. Phys., 14, 1963, 351.

15. E.W. Hart, Acta Metall., 5, 1957, 597.

16. A. Atkinson, R.I. Taylor, Phil. Mag. A, 43, 1981, 979.

17. C. Monty, A. Atkinson, Cryst. Latt. And Amorph., 18, 1989, 97.

18. C.J.A. Monty, Materials Science Forum, 207-209, 1996, 633.

19. A.C.S. Sabioni, A.M. Huntz, F. Silva, F. Jomard, Material Science and Engineering, A392, 2005, 254.

20. D. Prot, M. Miloche, C. Monty, J. Phys., Paris, 51, supl.1, 1990, 1027.

21. M. Kilo, Defect and Diffusion Forum, 242-244, 2005, 185.

22. R.D. Shannon: Acta Cryst. A, 32, 1976, 751.

23. C. Hellwig, M. Pouchon, R. Restani, F. Ingold, G. Bart: J. Nucl. Mater.,. 340, 2005, 163.

24. H. Solmon, J. Chaumont, C. Dolin, C. Monty, Ceram.Trans., 24, 1991, 175.

25. H. Solmon, C. Monty, M. Filal, G. Petot-Ervas, C. Petot, Solid State Phenomena, 41, 1995, 103.

26. S. Komine, Solid State Ionics, 178, 2007, 315.

27. K. Hoshino, N.L. Peterson, J. Am. Ceram. Soc., 66, 1983, C-202-203. 
28. L. Himmel, R.F. Mehl, C.E. Birchenall, Trans AIME, 197, 1953, 827.

29. A.C.S. Sabioni, A.M. Huntz, A.M.J.M. Daniel, W.A.A. Macedos, Philosophical Magazine, $85, \mathrm{n}^{\circ} 31,2005,3643$.

30. M.J. Graham, "High Temperature Oxidation”, Ed. A. Rapp, 1981. 


\section{Figure Captions}

1- SEM micrograph of polished and thermal-etched surface of the 8YSZ ceramic after sintering at $1723 \mathrm{~K}$ for $168 \mathrm{~h}$.

2- Ce-profile obtained by SIMS on as-deposited YSZ sample using the spin coating method (a), PVD method (b). Figure $2 \mathrm{c}$ gives an example of background for the Ce profile after a diffusion attempt performed at $873 \mathrm{~K}$ on a single crystal.

3- Penetration profile of cerium in 8 YSZ polycrystal after a diffusion treatment at $1373 \mathrm{~K}$ vs time(a); typical crater profile(b); vs the depth (c).

4-Analysis of the penetration profile obtained by SIMS for Ce diffusion at $1473 \mathrm{~K}$ in $10 \mathrm{YSZ}$ (a); Region 1 with a sharp slope corresponds to the effective diffusion including bulk and grain boundary diffusion(b). Region 2 with a weak slope is associated to grain boundary diffusion (c).

5- Analysis of the penetration profile obtained by SIMS for Gd diffusion at 1473K in 10YSZ (a); Region 1 with a sharp slope corresponds to the effective diffusion including bulk and grain boundary diffusion, and the slope of the straight line corresponds to the theoretical diffusion profile given by eqn.1 for effective diffusion (b). Region 2 with a weak slope is associated to grain boundary diffusion, and the slope of the straight line corresponds to the gradient - $\partial \ln$ $\mathrm{C} / \partial \mathrm{x}^{6 / 5}$ necessary to solve eqn.2 (c).

6- Penetration profiles obtained in the case of C-type regime experiments: diffusion of $\mathrm{Gd}$ at $1173 \mathrm{~K}$ in 8 YSZ polycrystal (a and b), diffusion of Ce at $1173 \mathrm{~K}$ in 8 YSZ polycrystal (c and d). As-obtained profiles (a and c), and analysis of the profile according to eqn. 4 (b and d).

7- Penetration profile of Ce in 9.5YSZ single crystal after diffusion at $1673 \mathrm{~K}$ for 2 days (a), and analysis (b).

8- Penetration profile of Ce in 9.5YSZ single crystal after diffusion at $1373 \mathrm{~K}$ for 1 month (a), analysis according to eqn.1 (b) and analysis according to eqn.2 (c).

9- Arrhenius plot of bulk and grain boundary diffusivities of Ce and Gd in 8YSZ (a) and 10YSZ (b) polycrystals.

10- Comparison of diffusivities according to the yttria content in stabilized zirconia.

11- Comparison, in an Arrhenius plot, of our results (polycrystals and single crystal) with literature data on bulk diffusion of cations. $\left(^{*}\right)$ corresponds to single crystal samples.

12- Comparison, in an Arrhenius plot, of our results with literature data on grain boundary diffusion of cations 
Table 1: Ce and Gd diffusion coefficients in cubic yttria-stabilized zirconia.

\begin{tabular}{|c|c|c|c|c|c|c|c|}
\hline Samples & $\begin{array}{l}\text { Diffusin } \\
\text { g species }\end{array}$ & $\begin{array}{l}\text { Deposition } \\
\text { technique }\end{array}$ & $\begin{array}{c}\text { Temperature } \\
(\mathbf{K}) \\
\end{array}$ & $\begin{array}{l}\text { Time } \\
\text { (days) }\end{array}$ & $\begin{array}{c}D_{\text {eff }} \\
\left(\mathrm{cm}^{2} \cdot \mathbf{s}^{\mathbf{1}^{1}}\right)\end{array}$ & $\begin{array}{c}D_{b} \\
\left(\mathrm{~cm}^{2} \cdot \mathrm{s}^{-1}\right)\end{array}$ & $\begin{array}{c}\alpha D_{g b} \\
\left(\mathbf{c m}^{2} \cdot \mathbf{s}^{-1}\right)\end{array}$ \\
\hline \multirow{11}{*}{$\begin{array}{c}\text { 8YSZ } \\
\text { Polycrystal }\end{array}$} & \multirow{7}{*}{$\mathrm{Ce}^{4+}$} & $\mathrm{Sp}$ & 1673 & 2 & $8.310^{-15}$ & $4.910^{-16}$ & $1.310^{-11}$ \\
\hline & & PVD & 1673 & & $1.610^{-14}$ & $3.310^{-16}$ & $2.610^{-11}$ \\
\hline & & $\mathrm{Sp}$ & 1473 & 19 & $6.610^{-17}$ & $2.910^{-18}$ & $1.110^{-13}$ \\
\hline & & $\mathrm{Sp}$ & 1373 & 30 & $4.410^{-18}$ & $1.510^{-19}$ & $7.210^{-15}$ \\
\hline & & & $1373 *$ & & $4.610^{-18}$ & $8.410^{-20}$ & $7.610^{-15}$ \\
\hline & & & $1373 * *$ & & $4.510^{-18}$ & $1.810^{-19}$ & $7.310^{-15}$ \\
\hline & & $\mathrm{Sp}$ & 1173 & 60 & & & $2.410^{-18}$ \\
\hline & \multirow{4}{*}{$\mathrm{Gd}^{3+}$} & $\mathrm{Sp}$ & 1673 & 2 & $5.210^{-15}$ & $7.510^{-17}$ & $8.510^{-12}$ \\
\hline & & $\mathrm{Sp}$ & 1573 & 8 & $6.610^{-16}$ & $1.110^{-17}$ & $1.110^{-12}$ \\
\hline & & $\mathrm{Sp}$ & 1473 & 19 & $5.210^{-17}$ & $1.110^{-18}$ & $8.410^{-14}$ \\
\hline & & $\mathrm{Sp}$ & 1173 & 60 & & & $1.710^{-18}$ \\
\hline \multirow{10}{*}{$\begin{array}{c}\text { 10YSZ } \\
\text { Polycrystal }\end{array}$} & \multirow{5}{*}{$\mathrm{Ce}^{4+}$} & $\mathrm{Sp}$ & 1673 & 2 & $4.210^{-15}$ & $2.710^{-16}$ & $6.510^{-12}$ \\
\hline & & PVD & 1673 & & $8.510^{-15}$ & $2.910^{-16}$ & $1.410^{-11}$ \\
\hline & & $\mathrm{Sp}$ & 1473 & 19 & $2.910^{-16}$ & $6.810^{-18}$ & $4.710^{-13}$ \\
\hline & & $\mathrm{Sp}$ & 1373 & 30 & $5.910^{-18}$ & $8.710^{-19}$ & $8.410^{-15}$ \\
\hline & & $\mathrm{Sp}$ & 1173 & 60 & & & $1.210^{-19}$ \\
\hline & \multirow{5}{*}{$\mathrm{Gd}^{3+}$} & $\mathrm{Sp}$ & 1673 & 2 & $3.710^{-15}$ & $1.110^{-16}$ & $5.910^{-12}$ \\
\hline & & $\mathrm{Sp}$ & 1573 & 8 & $4.310^{-16}$ & $4.010^{-18}$ & $7.010^{-13}$ \\
\hline & & $\mathrm{Sp}$ & 1473 & 19 & $6.410^{-17}$ & $7.710^{-19}$ & $1.110^{-13}$ \\
\hline & & $\mathrm{Sp}$ & 1373 & 30 & $2.010^{-18}$ & $8.710^{-21}$ & $3.310^{-15}$ \\
\hline & & $\mathrm{Sp}$ & 1173 & 60 & 0 & & $1.210^{-19}$ \\
\hline \multirow{4}{*}{$\begin{array}{l}\text { 9.5YSZ } \\
\text { Single } \\
\text { crystal }\end{array}$} & \multirow{4}{*}{$\mathrm{Ce}^{4+}$} & $\mathrm{Sp}$ & 1673 & 2 & & $5.910^{-15}$ & \\
\hline & & PVD & 1673 & & & $410^{-15}$ & \\
\hline & & $\mathrm{Sp}$ & 1473 & 19 & & $6.010^{-17}$ & \\
\hline & & $\mathrm{Sp}$ & 1373 & 30 & & $8.810^{-18}$ & \\
\hline
\end{tabular}

$\mathrm{Sp}=$ spin coating deposition method. * Analysis of the concentration profile, $* *$ analysis of the concentration profile after subtracting the background. 
Table 2 : Activation energy $(\mathrm{kJ} / \mathrm{mol})$ for bulk and grain boundary diffusion of $\mathrm{Ce}$ and $\mathrm{Gd}$ in yttria-stabilized zirconia

\begin{tabular}{|c|c|c|c|}
\hline Diffusing element & Zirconia samples & $\begin{array}{c}\text { A.E. for } \mathrm{D}_{\mathrm{b}} \\
(\mathrm{kJ} / \mathrm{mol})\end{array}$ & $\begin{array}{c}\text { A.E. for } \alpha \mathrm{D}_{\mathrm{gb}} \\
(\mathrm{kJ} / \mathrm{mol})\end{array}$ \\
\hline \multirow{3}{*}{$\mathrm{Ce}$} & $8 \mathrm{YSZ}$ & $516( \pm 7)$ & $506( \pm 12)$ \\
\cline { 2 - 4 } & $10 \mathrm{YSZ}$ & $366( \pm 8)$ & $599( \pm 88)$ \\
\cline { 2 - 4 } & $\begin{array}{c}9.5 \mathrm{YSZ} \\
(\text { single crystal })\end{array}$ & $420( \pm 39)$ & $507( \pm 8)$ \\
\hline \multirow{2}{*}{$\mathrm{Gd}$} & $8 Y S Z$ & $433( \pm 7)$ & $582( \pm 19)$ \\
\hline
\end{tabular}




\section{Figure 1}

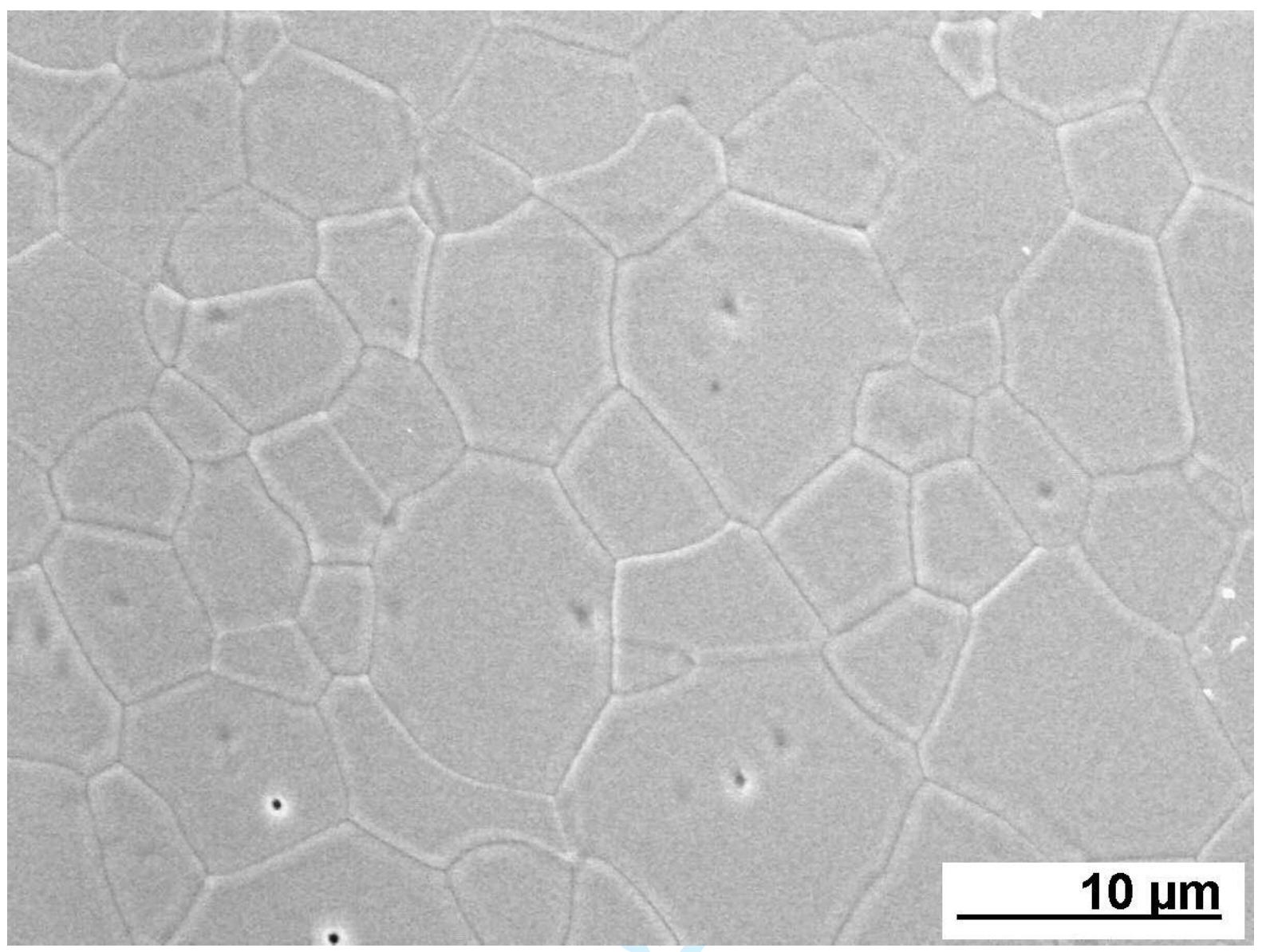




\section{Figure 2}

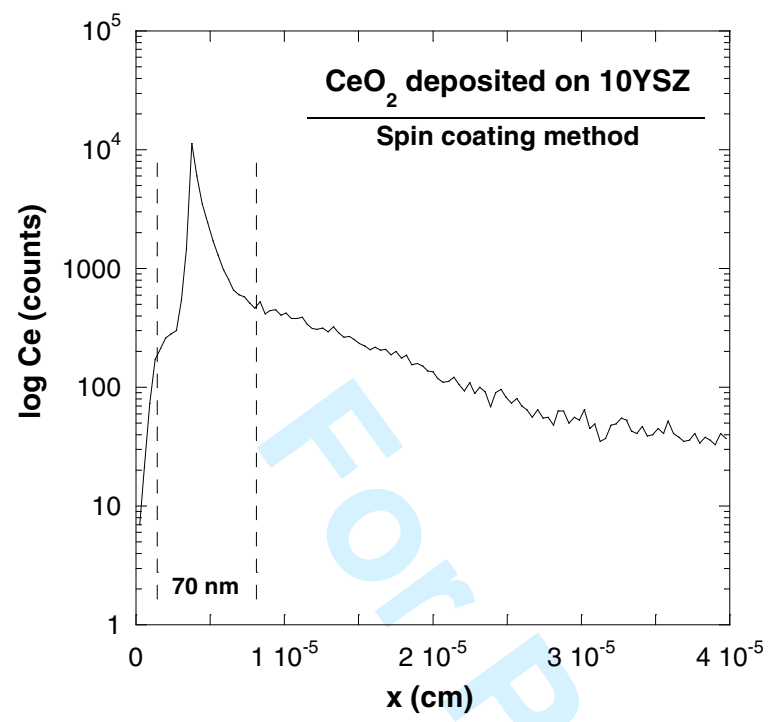

(a)

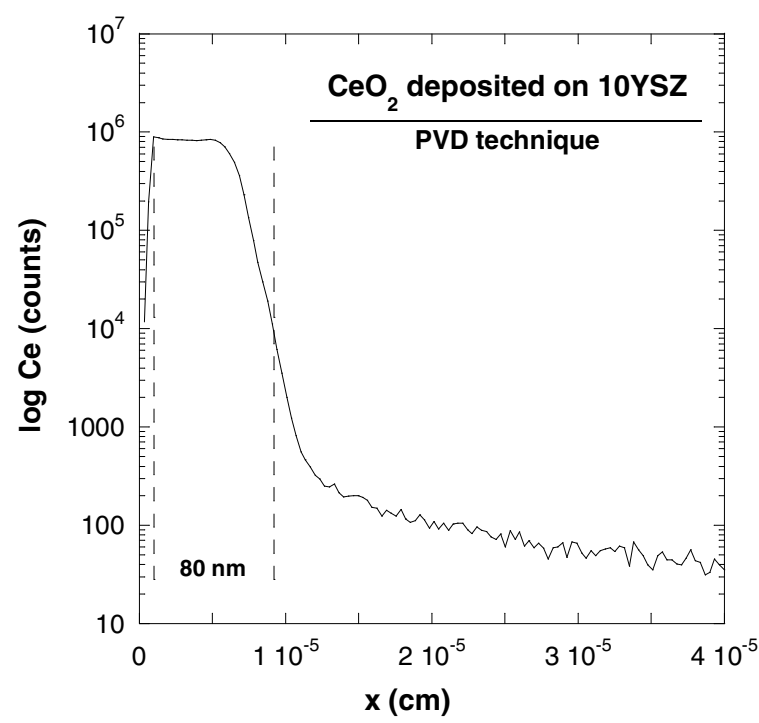

(b)

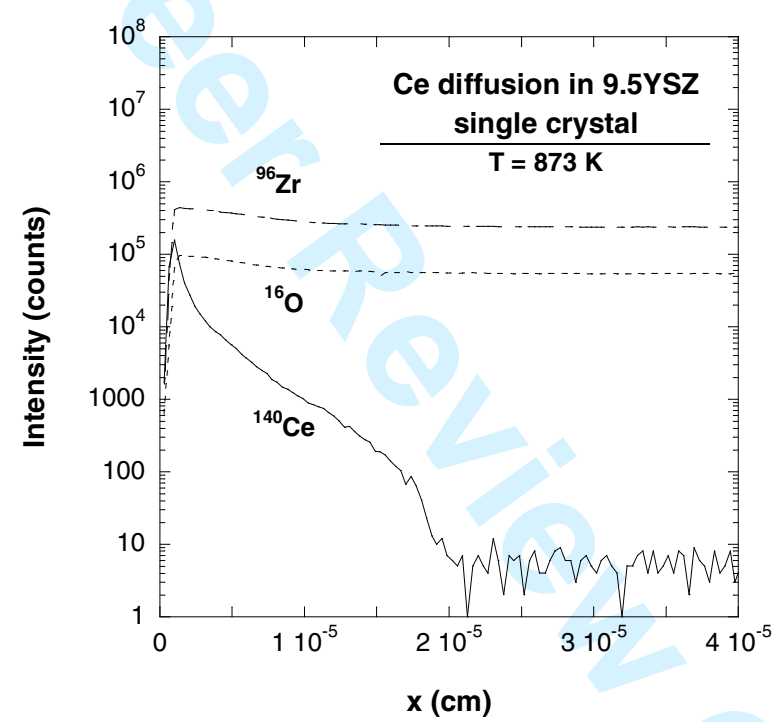

(c) 


\section{Figure 3}

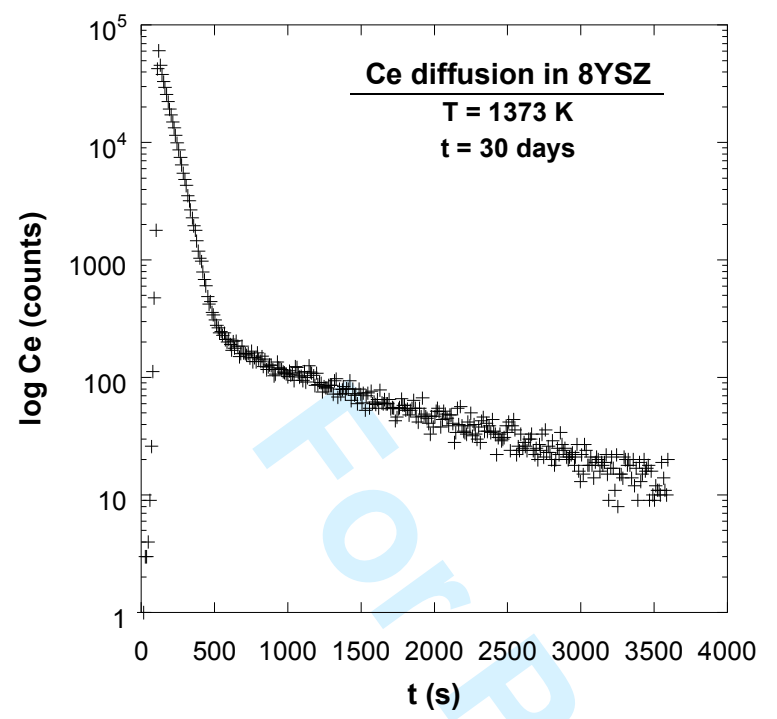

(a)

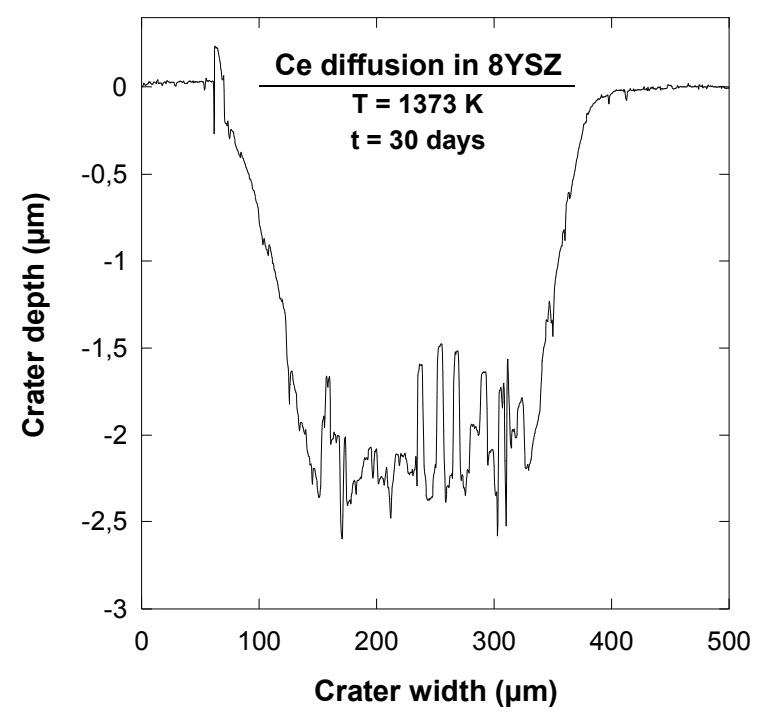

(b)

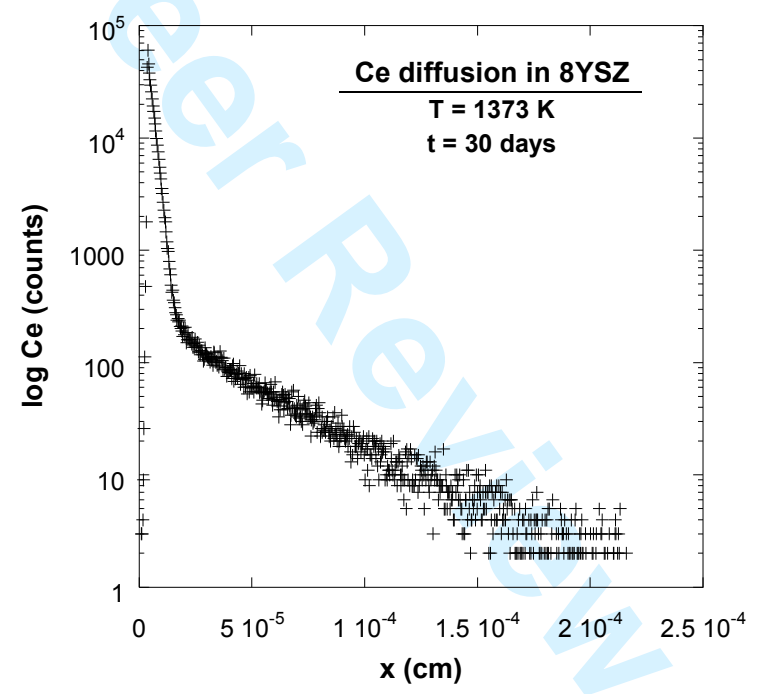

(c) 


\section{Figure 4}

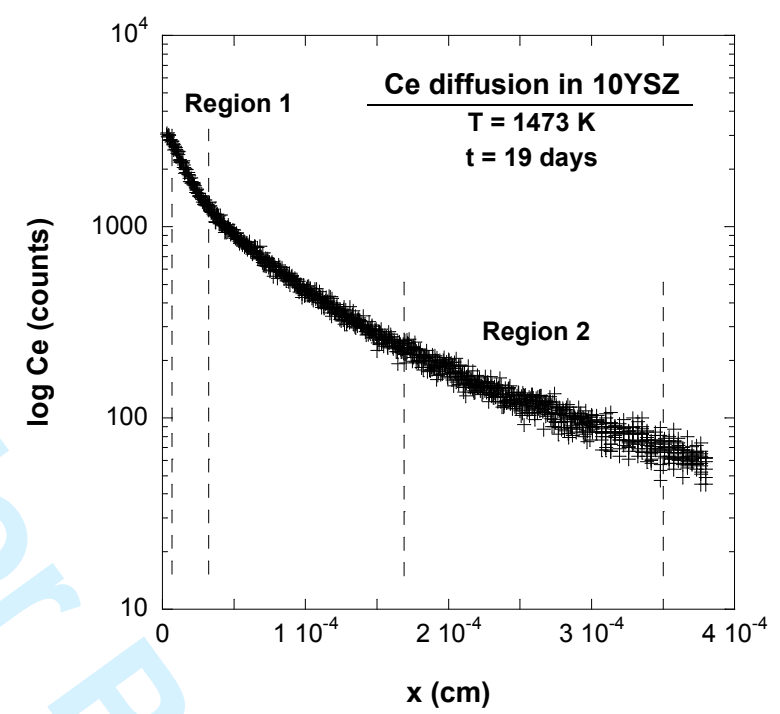

(a)

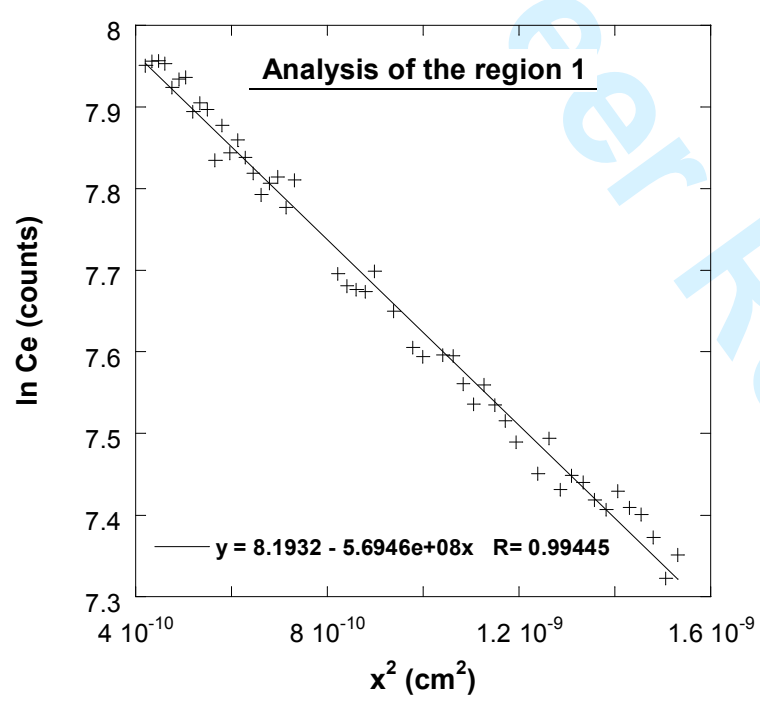

(b)

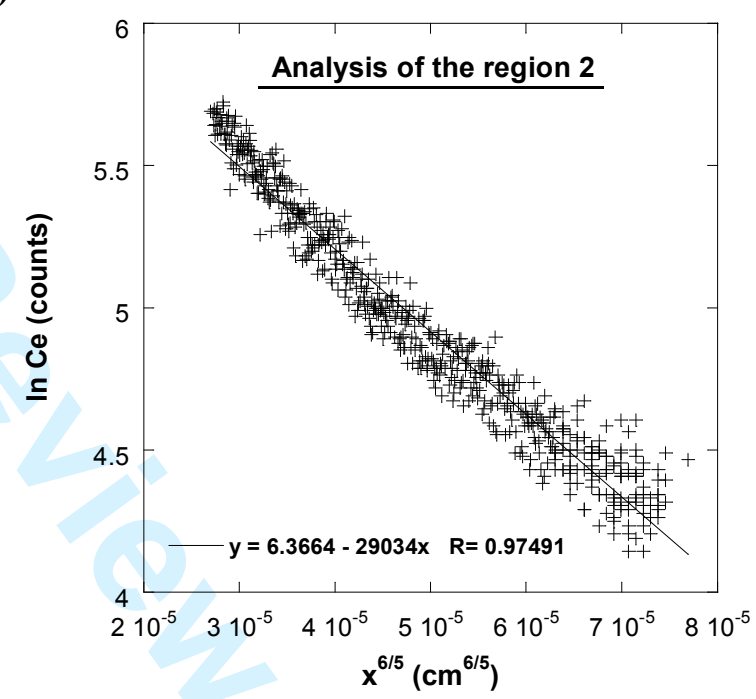

(c) 


\section{Figure 5}

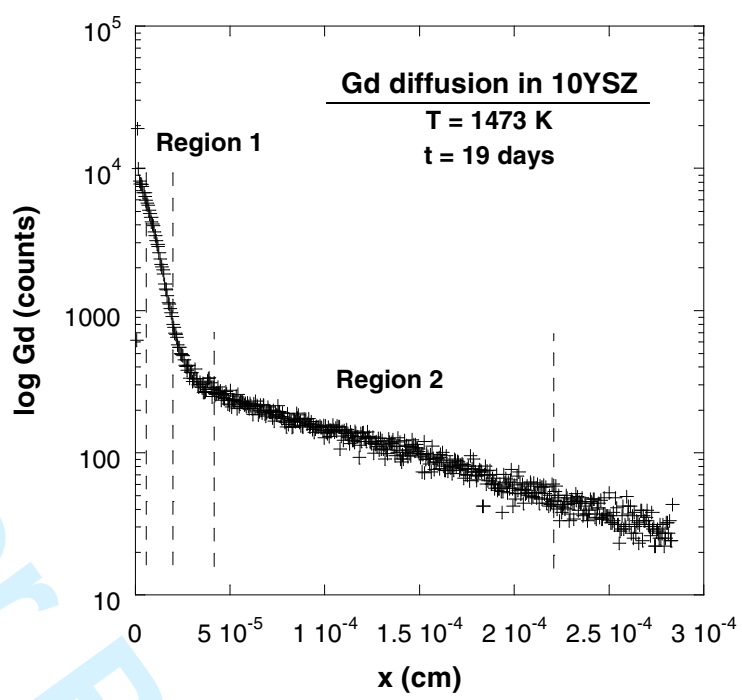

(a)

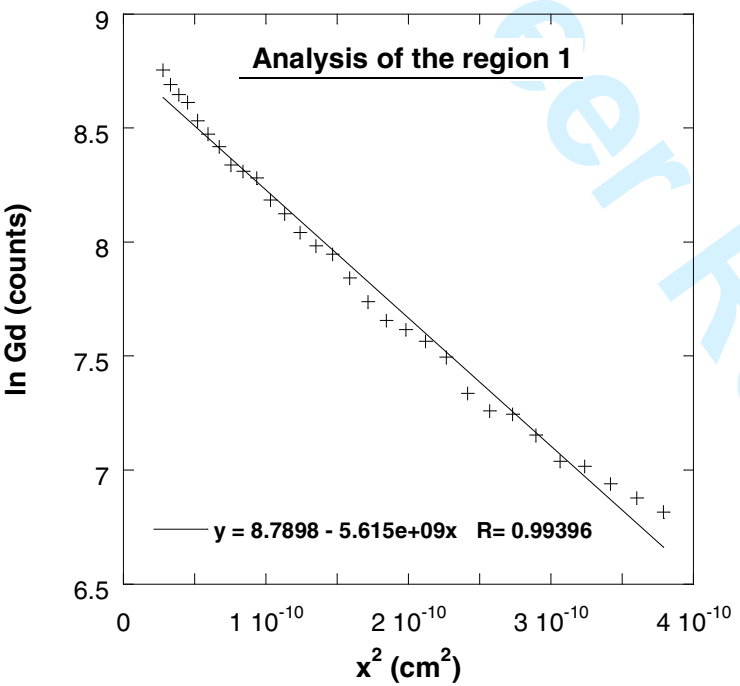

(b)

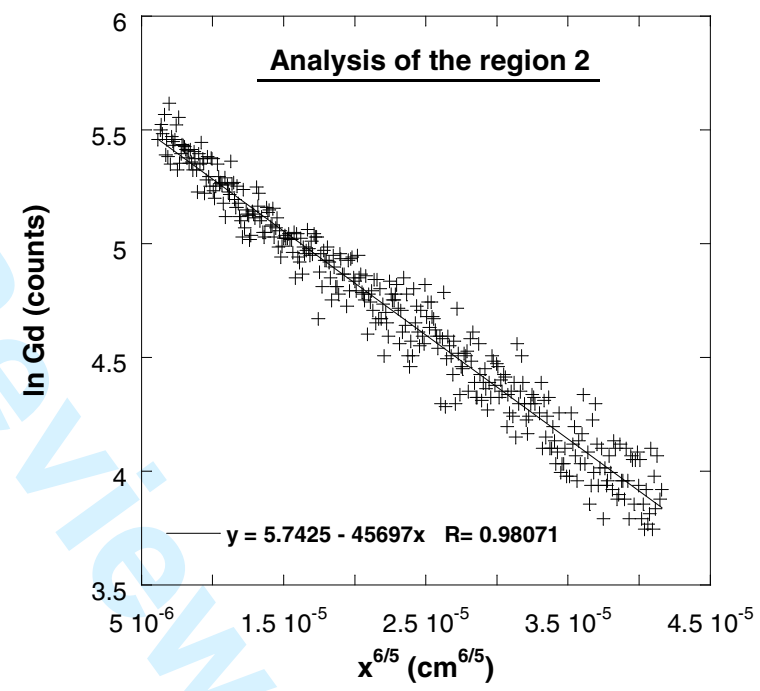

(c) 


\section{Figure 6}

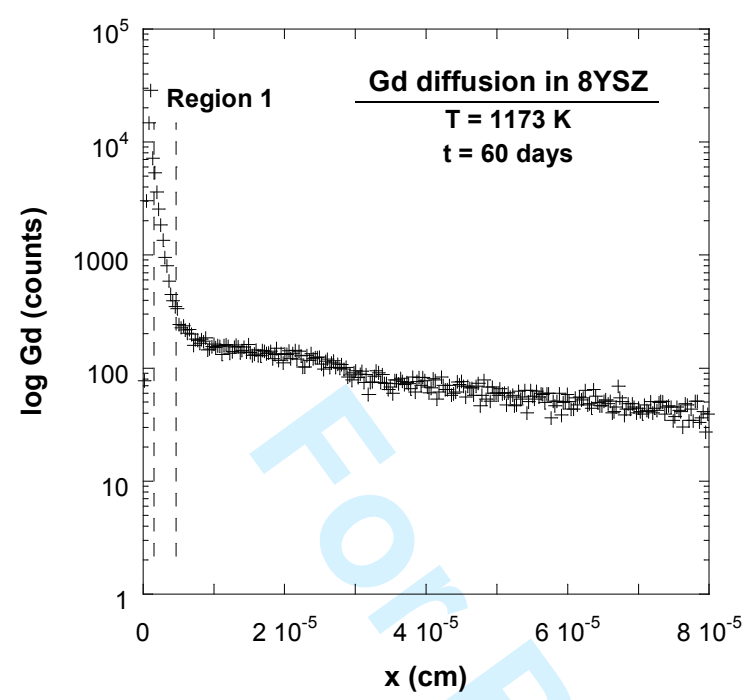

(a)

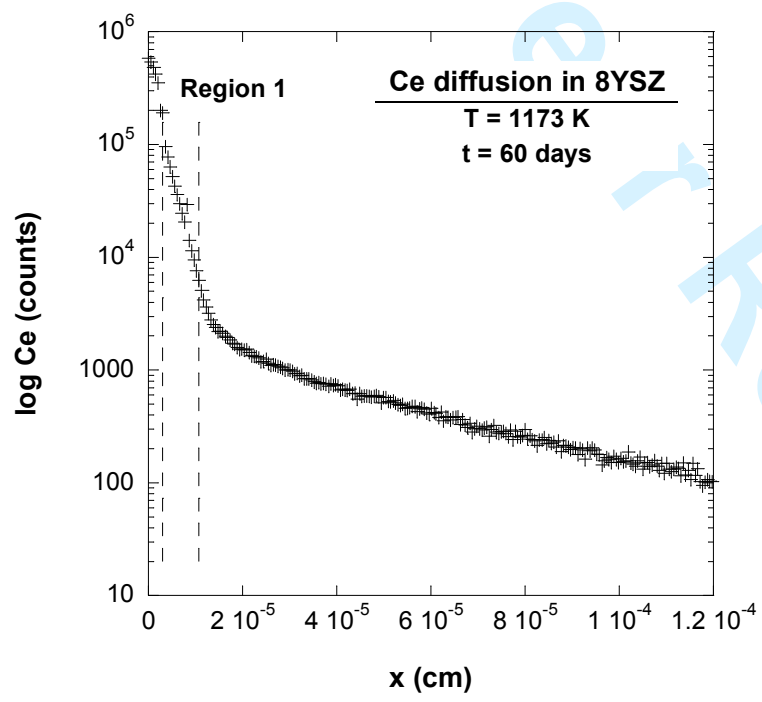

(c)

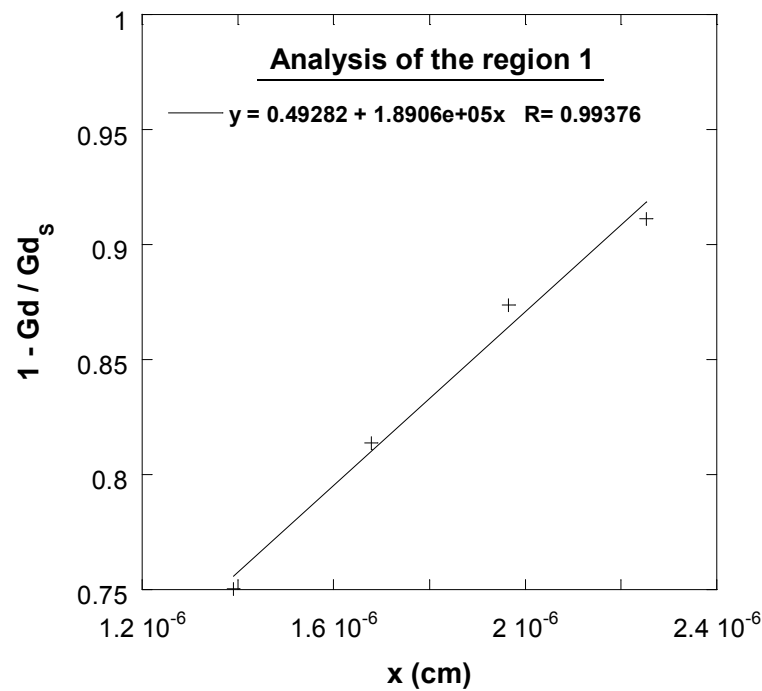

(b)

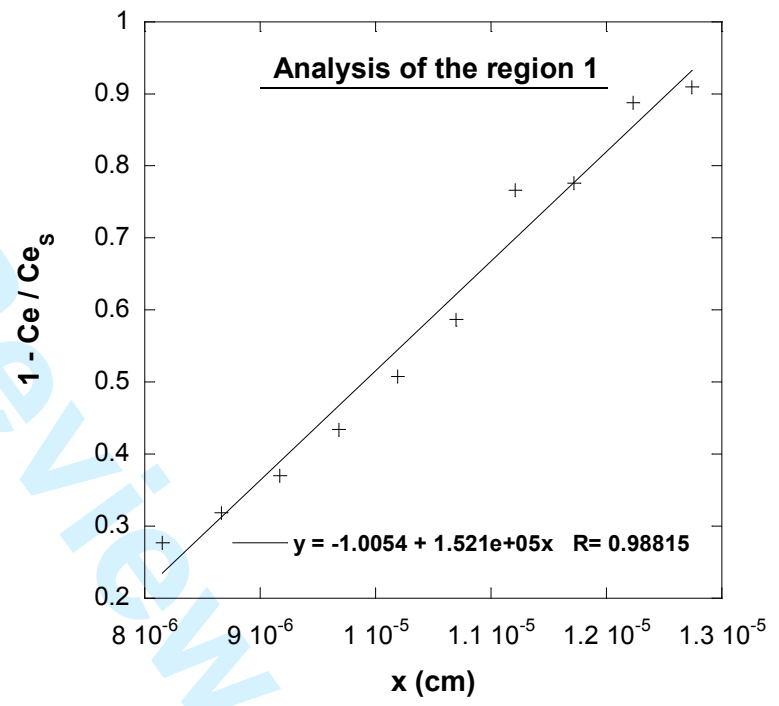

(d) 


\section{Figure 7}
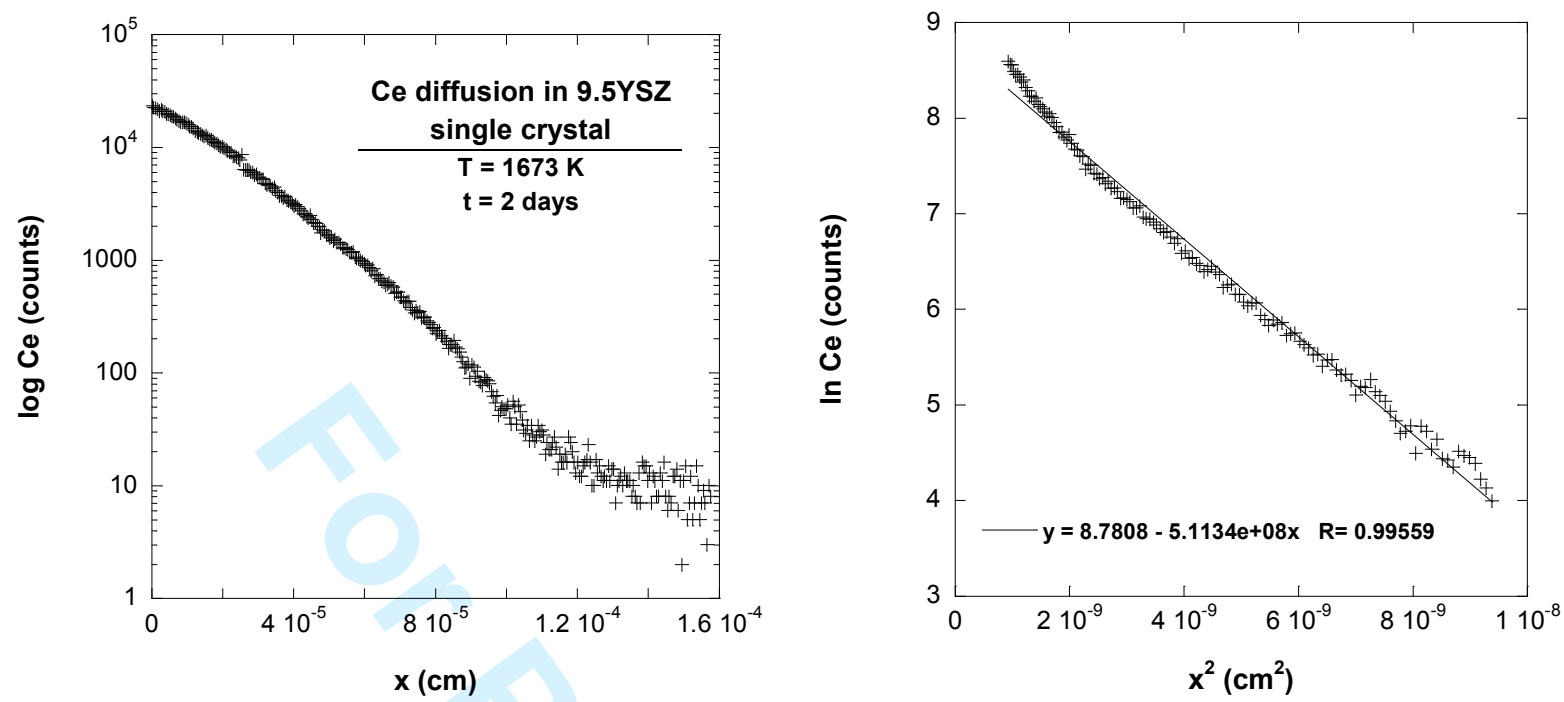

(a)

(b) 


\section{Figure 8}

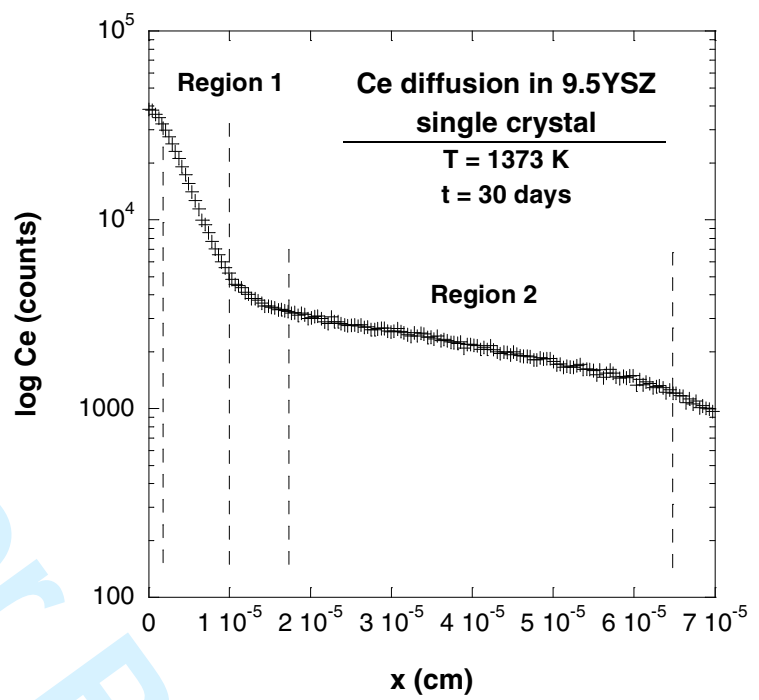

(a)

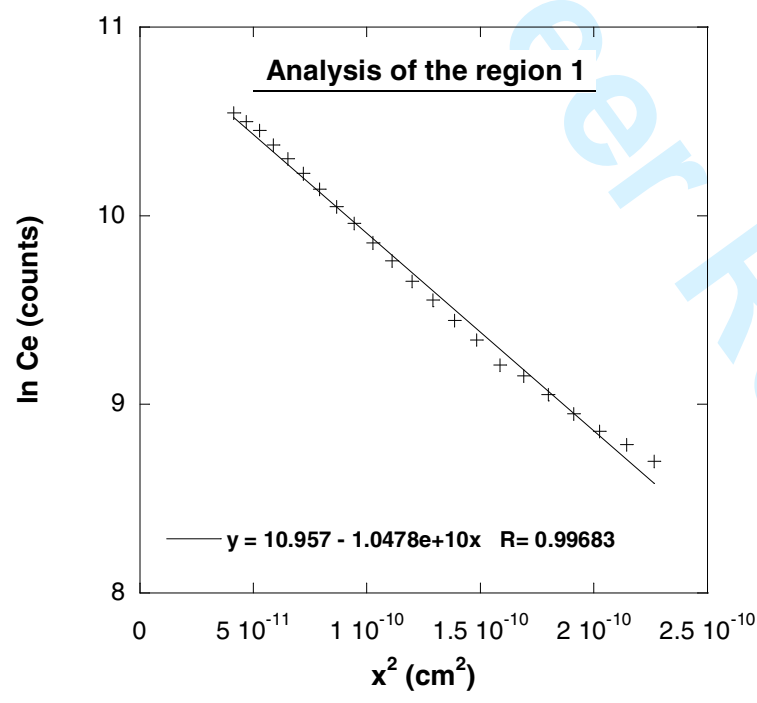

(b)

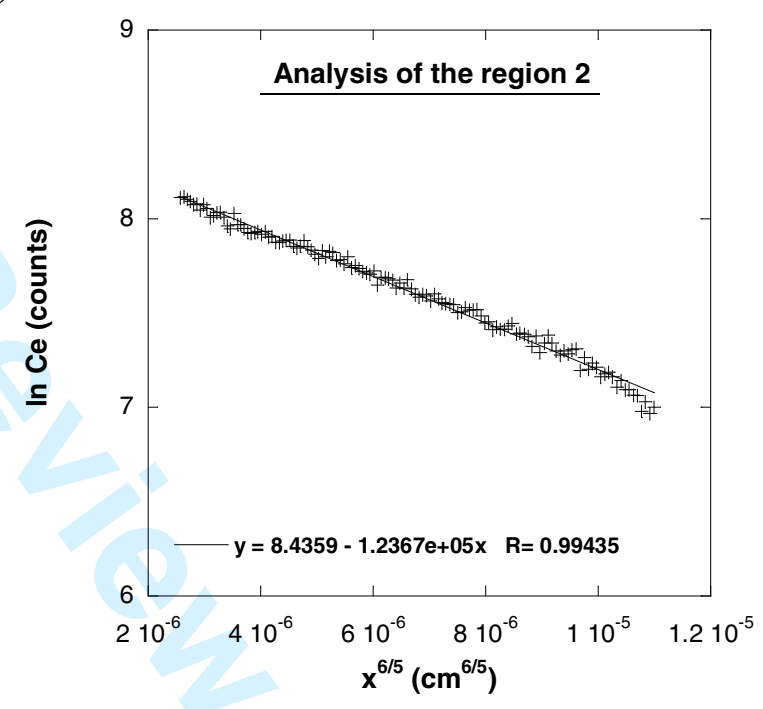

(c) 


\section{Figure 9}

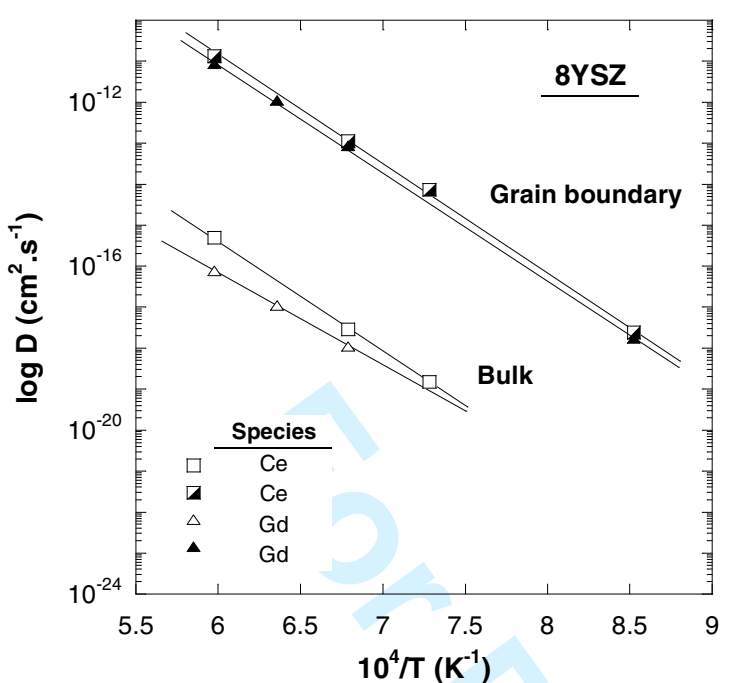

(a)

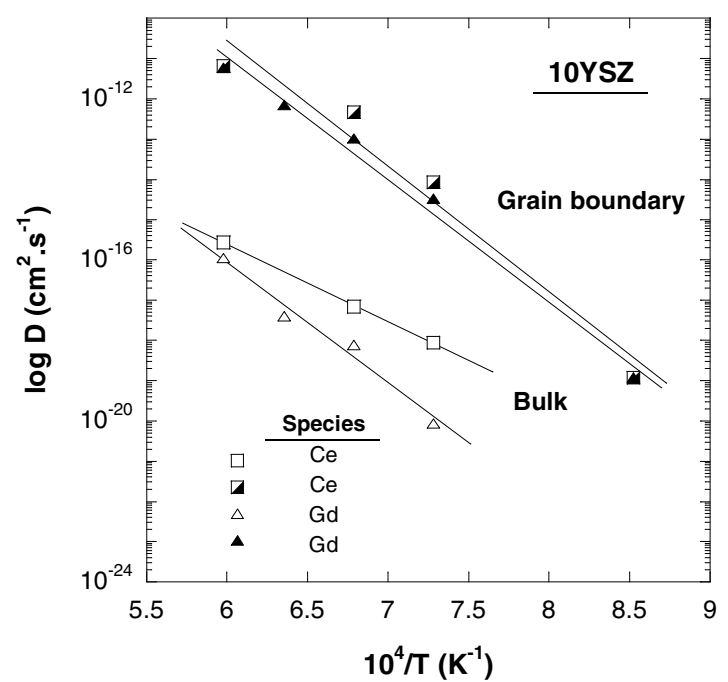

(b) 
Figure 10

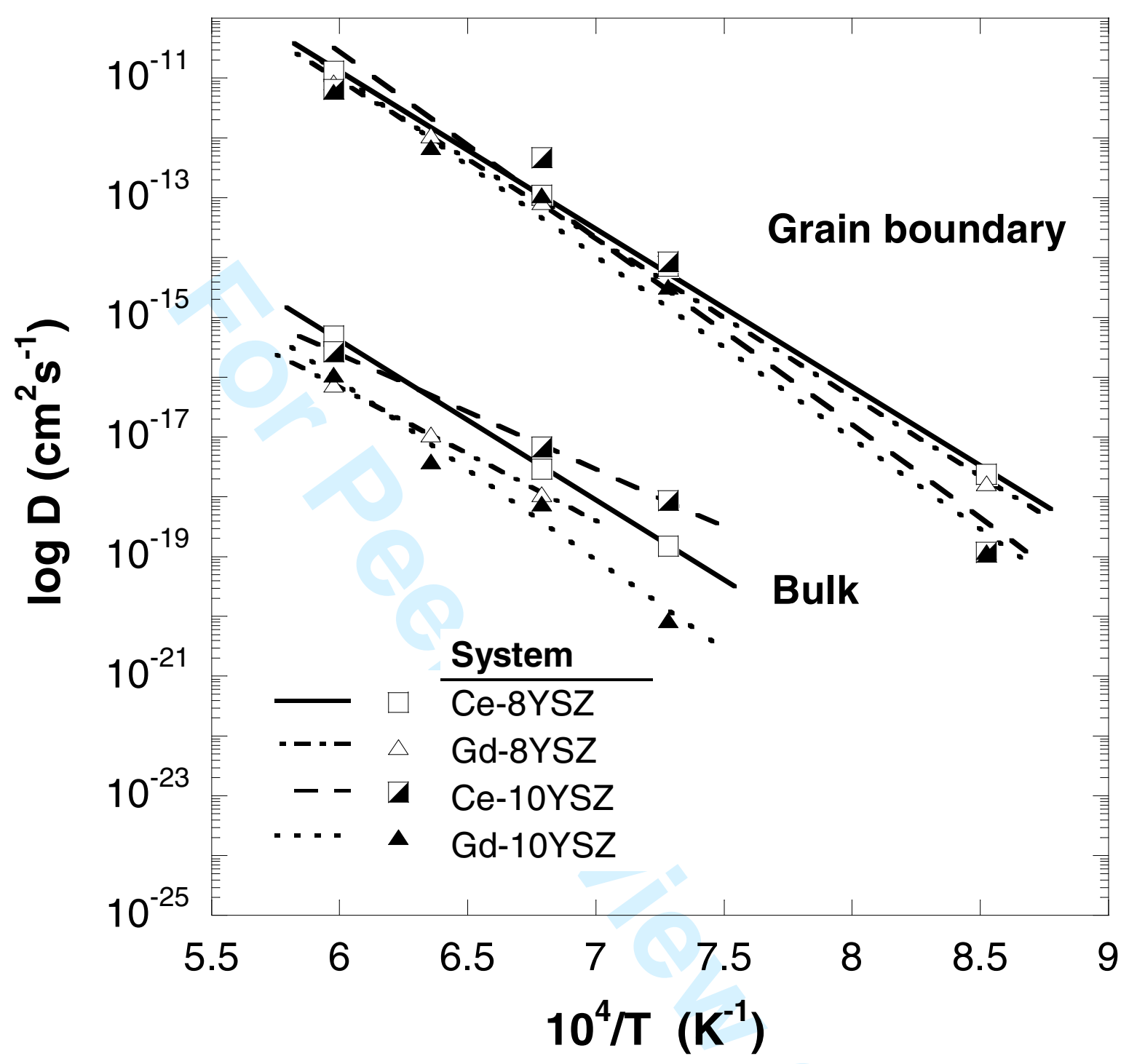




\section{Figure 11}

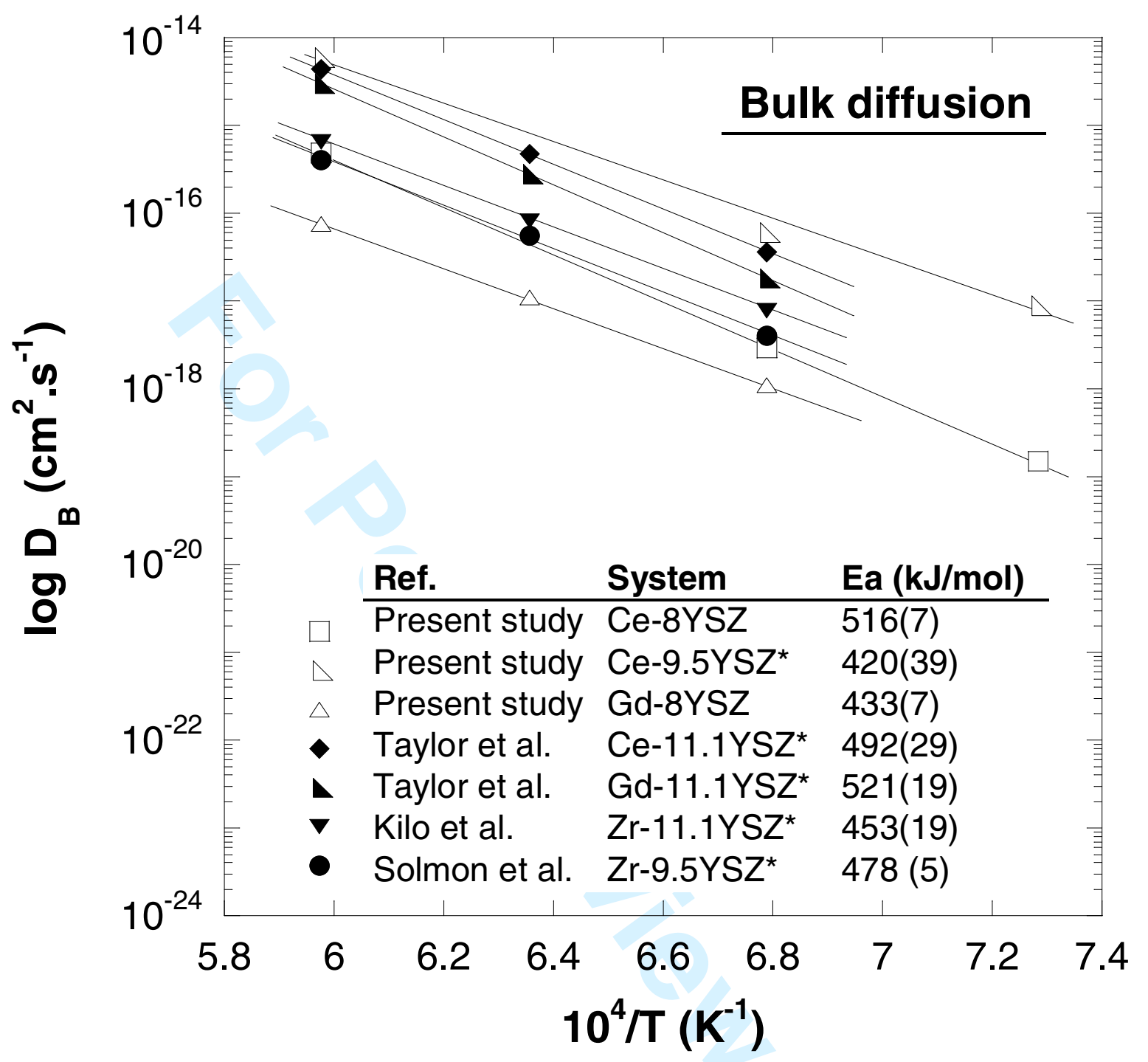


Figure 12

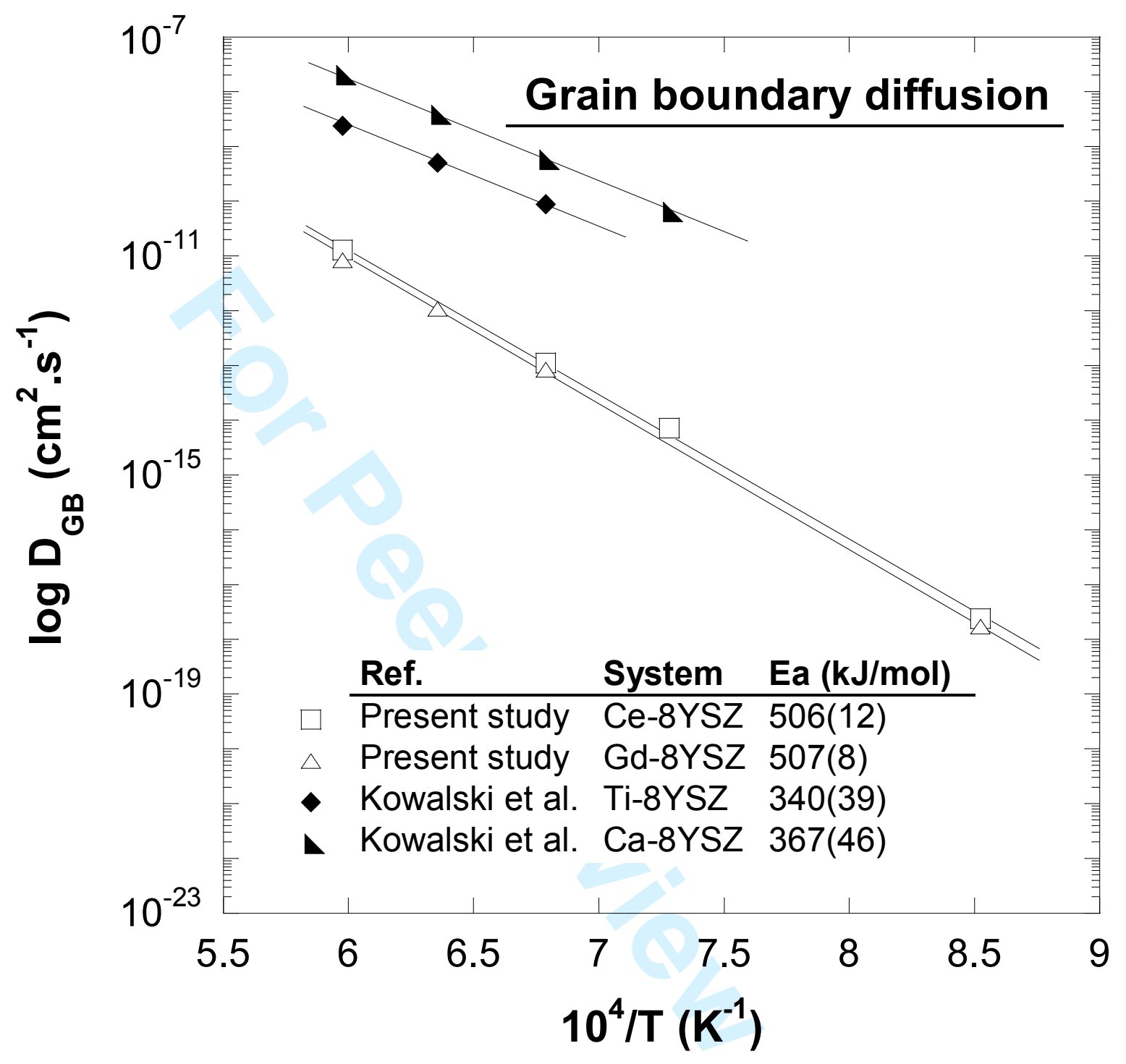

